\title{
ALGUNAS CONTRIBUCIONES ESPAÑOLAS AL ESTUDIO DE LA PRUDENCIA
}

SUMARIo: 1. Preliminares sobre la prudencia en la Antigüedad clásica y especialmente en Aristóteles. 2. Razones para la elección de este tema. 3. Repulsa de la separación radical entre teoria y vida. 4. ¿Por qué estudiar las aportaciones del pensamiento español al tema de la prudencia? 5. Algunas figuras y directrices ilustres de los siglos xvi y xvir. 6. Siglos xvII y xix. 7. Contribución de Leopoldo Eulogio Palacios. 8. Las contribuciones de Miguel de Unamuno y de José Ortega y Gasset.

1. Preliminares sobre la prudencia en la Antigüedad clásica y especialmente en Aristóteles

La significación, la importancia y el alcance de los criterios de la prudencia fueron tema de interés primordial en la cultura de la Antigüedad clásica, sobre todo de la griega, y en la cultura del Medievo, e incluso en los primeros tiempos de la Edad Moderna hasta mediados del siglo xviII.

Pero más tarde el estudio de la prudencia fue víctima de descuido o incluso de olvido, por virtud de la exacerbación frenética del racionalismo formalista, esto es, de lo que se ha llamado el espíritu cartesiano, el ideal matematizante; y después por la exaltación de la moral rigorista y formalista de Kant.

Pero hoy en día se redescubre lo que los griegos habían no sólo sospechado, sino también intuido, a saber: que el hombre, este ser tan extraño, no es precisamente lo que debe ser rebasado o trascendido, sometiéndolo a esquemas de razón pura formalista, antes bien, es lo que debe ser conservado en su auténtica realidad. Se descubre que lo superhumano es lo que más se parece a lo inhumano; y se cae en la cuenta de que lo mejor, lo óptimo, suele convertirse en el enemigo de lo bueno; que lo racional muchísimas veces no es razonable para la existencia del hombre; y que frecuentemente la tentación de los criterios absolutos es la fuente, que una y otra vez renace, de las desgracias del ser humano. ${ }^{1}$

Mucho se ha escrito y discutido sobre las diversas versiones de la fronésis o prudencia de Aristóteles. ${ }^{2}$ Pues sucede que esta palabra en las diversas y sucesivas obras aristotélicas aparece con sentidos diferentes. Primero, dicho vocablo es usado como sinónimo de la sophia, es decir, de la ciencia, de la

1 Véase: Pierre Aubenque, La prudence chez Aristôte, Presses Universitaires de France, 1963 , pp. 2 ss.

2 Por ejemplo, véase: O. F. Bolnow, Wesen und Wandel der Tugenden, Francfort, 1958; Dirlmeier, Aristoteles, Magna Moralia, 1958; Pierre Aubenque, op. et loc. cit.; Werner 
episteme, como conocimiento de lo inmutable, como saber auténticamente verdadero. Pero más tarde, en la Ética a Nicómaco, dicho vocablo designa otra cosa por completo diferente: designa el conocimiento calculativo, la opinión, la apreciación práctica, la evaluación de las realidades, las razones para la conducta; y todo ello encaminado a la indagación de los bienes humanos, de aquello que es a la vez bueno y también conveniente, adecuado, apropiado. En suma: denota el conocimiento de lo contingente, de lo que es variable según los distintos individuos y las diversas circunstancias. La prudencia aparece como siendo sobre todo el componente principal de la vida buena, el fundamento de la acción correcta: es la razón práctica, diferente de la razón teórica; es lo razonable, diferente de lo racional; es un sentido ético capaz de orientar la acción humana hacia lo que es no sólo bueno sino también adecuado para el hombre y para las situaciones varias en las que éste se encuentra.

Jaeger hace notar las diferencias de la fronésis en los varios textos aristotélicos. ${ }^{3}$ Desde el Protéptico hasta la Etica a Eudemo, la prudencia aparece todavía ligada a la sabiduría en un cierto sentido platónico, como contemplación especulativa de unas ideas referidas a la acción. Por el contrario, en la obra posterior, en la Ética a Nicómaco, la fronésis está ya desprovista de una significación teórica o científica y se muestra como una especie de intuición moral, sin referencias a normas trascendentes.

Aubenque 4 cree que debemos atenernos a los textos de la Ética a Nicómaco, así como también a los de la Gran Moral, que son los que contienen la elaboración madura y original de Aristóteles sobre la prudencia. La prudencia es un saber de lo particular, que permite aplicar los principios de la ética, y tal como ellos son definidos por la conciencia moral o sindéresis, a la variabilidad indefinida de las circunstancias, sobre las cuales se tiene que ejercer la acción humana. No se debe considerar que exista propiamente un corte, una ruptura, entre las leyes morales rígidas, uniformes e intangibles, por una parte, y la movilidad fugaz de los actos múltiples y diversos, insertos todos y cada uno de ellos en las circunstancias variables que forman la trama de nuestra vida, por otra parte. Esta es la interpretación dada por Tomás de Aquino, la cual se considera como la que tiene el mayor grado de autenticidad. Aunque la prudencia sea un tipo de conocimiento especial, requerido por su carácter práctico, sin embargo, no deja de ser un conocimiento. Cierto

Jaeger, Aristoteles: Grunlegung einer Geschichte seiner Entwicklung, 1923; "Ueber Ursprung und Kreislauf des philosophischen Lebensideals", en Sitzungsberichte der preussischen Akademie der Wissenschaften, 1928; Das Verhältnis der eudemischen zur nikomachischen Ethik, Berlín, 1912; J. Walter, Die Lehre von der praktischen Vernunft in der griechischen Philosophie, Jena, 1874; P. Gauthier, La morale d'Aristôte, 1950; Bertrand Russell, $A$ History of Western Philosophy, New York, 1945, pp. 15-16.

3 Op. cit. en la nota precedente.

4 Op. cit. 
que en tanto que es práctica, es decir, imperativa, la prudencia incluye el deseo y la virtud; pero en tanto que es intelectual, comprende no sólo la ponderación de los medios, sino también la elección de las finalidades.

No puede hablarse de la prudencia sin que nos preguntemos al mismo tiempo sobre el por qué el hombre debe ser prudente en este mundo; prudente, más bien que sabio o simplemente virtuoso. El problema de la pruden. cia y, secundariamente, de las variaciones de su sentido, no puede ser resuelto sino en tanto que se la trate en un plano metafísico. La prudencia tiene por objeto lo contingente, lo cual, cuando somos afectados por ello, se llama azar. La prudencia, por otra parte, es sabiduría del hombre y para el hombre.

En el libro III de la Ética a Nicómaco, Aristóteles define la prudencia como una "disposición práctica acompañada de una regla correcta concer. niente a lo que es bueno y lo que es malo para el hombre". La prudencia implica la capacidad de deliberación. Ahora bien, recuérdese que no se delibera más que sobre lo contingente; mientras que la ciencia se refiere a lo necesario. Por lo tanto, la prudencia no es una ciencia. No es tampoco un arte, porque el arte se refiere a la producción de obras, mientras que la prudencia apunta a la conducta o acción humana. Aunque la prudencia se refiere a la conducta práctica, ella implica o presupone una regla para la elección. No se trata aquí de la rectitud íntima de la acción, sino de la corrección o acierto del criterio empleado. Pero esa regla implicada por la prudencia no se refiere al bien y al mal en términos generales y absolutos, antes bien, concierne sólo a lo bueno y a lo malo para el hombre, en unas determinadas circunstancias.

En fin de cuentas, Aristóteles refiere el meollo de la prudencia al ejemplo de lo que hacen los hombres prudentes y de cómo éstos se comportan.

Yo creo que Aristóteles intuyó certeramente la médula de la prudencia. Creo además que tuvo el fenomenal mérito no sólo de haber llamado la atención sobre los razonamientos propios de la prudencia, los cuales son diferentes de la razón de la ciencia, sino que, además, comenzó a desbrozar el camino para la investigación de ese tipo de logos de la conducta humana práctica, y de la resolución de los conflictos entre los hombres, de ese logos que de pasada calificó como lo razonable, en contraste con lo racional absoluto.

Pero en los sucesivos textos aristotélicos, incluso en los de la Ética a Nicómaco y de la Gran Moral, persisten todavía algunas vaguedades e imprecisiones.

Tal vez las interpretaciones de Tomás de Aquino contribuyeron a afinar un poco este tema.

Pero me parece que la tarea de volver a plantear, con un deseo de más estricto rigor, este tema, y la faena de indagarlo, si fuese posible hasta sus postrimerías, es un quehacer que se le ha deparado al pensamiento del si- 
glo $x x$. Y en ese quehacer estamos trabajando mucha gente, y lo hacemos en gran parte bajo el estímulo de algunas de las más prominentes filosofias que se han producido en nuestra centuria.

Por otra parte, el tema de este trabajo no es el de conseguir una doctrina sobre la prudencia, antes bien tan sólo el de presentar algunas de las aportaciones españolas a este asunto, aportaciones en el pretérito, pero también y sobre todo en el siglo $\mathrm{xx}$.

\section{Razones para la elección de este tema}

Desearía justificar el por qué para este trabajo elegí el tema de la prudencia, no vista sólo en sus caracteres generales, sino de modo específico, precisamente en cuanto a las aportaciones españolas a dicho asunto. Pero veamos primero el interés que este tema provoca en sus términos generales.

El tema de la prudencia, en términos generales, es un asunto candente en el pensamiento de hoy, en el mundo occidental. Es actualísimo porque la filosofía de nuestros días ha mostrado, decisiva y definitivamente, que los problemas humanos prácticos, los domésticos, los sociales, los económiccs, los políticos y los jurídicos, no pueden, no deben ser tratados mediante la lógica pura tradicional, de tipo matemático; no deben ser resueltos por medio de raciocinios silogísticos, los cuales, cuando no son estériles, se muestran impertinentes e inoportunos, y además resultan perturbadores y conducentes a veces a efectos monstruosos.

El funesto error, sobre todo de los siglos xviII y xix, consistió en haber supuesto equivocadamente que la lógica pura formal del silogismo era toda la lógica. Pues bien, hoy en día, se ha redescubierto que esa lógica de la inferencia, aunque sea una parte muy importante de la lógica, no es toda la lógica, antes bien, es tan sólo una limitada provincia de la lógica. Dentro de la totalidad conjunta de la lógica, hay, entre otras zonas de la misma, la provincia o región del logos de lo humano o logos de lo razonable.

La lógica pura formal de la inferencia, del silogismo, es buena y es indispensable para la matemática y para la física; pero es inepta y catastrófica para tratar de resolver los problemas prácticos de conducta humana, las cuestiones sociales, económicas, políticas y juridicas. Así lo reconoció ya Aristóteles y lo dijo en sus obras no menos de 37 veces. ${ }^{5} \mathrm{Y}$ Aristóteles sostuvo que para el tratamiento de estas cuestiones encontramos los instrumentos adecuados en la retórica, la dialéctica (diálogo y deliberación) y la tópica.

Al lado de aquella lógica pura formalista de lo racional, apta para la matemática y la física, hay otra zona de la lógica, la lógica de lo razonable, que versa sobre los asuntos humanos. Esta lógica de lo humano, de lo razo-

5 Véase: Luis Recaséns Siches, "La lógica de los problemas humanos", en Diánoia, Anuario de Filosofia, México, 1964 . 
nable, está impregnada de juicios valoradores, de conocimientos sobre las realidades prácticas; está permeada por enlaces entre estas realidades y los valores que deben regir para el tratamiento de las mismas; contiene además nexos entre propósitos humanos y valores; y se ocupa de los vínculos entre los propósitos y los medios. Ese logos de lo razonable además carga sobre sus espaldas las lecciones sacadas de la experiencia de la vida. ${ }^{6}$

Ahora bien, esa lógica propia para tratar los asuntos humanos puede ser considerada como el meollo sustancial de lo que se ha querido indicar con la palabra "prudencia".

A lo largo de los últimos 80 años se ha producido un número de ofensivas, cada día con mayor energía y en más grande cantidad, contra los insensatos intentos de aplicar el espíritu cartesiano, el método matematizante o geometrizante a los asuntos humanos, a la política y al Derecho, contra el espíritu axiomático y la absoluta exactitud en las cuestiones de conducta práctica.

Claro es que no desdeñamos los pasmosos avances que la razón pura ha traído para la ciencia y para la tecnología, cuyas hazañas de hoy suscitan entusiasta asombro.

Pero no se pueden hacer leyes buenas a base de deducciones de tipo matemático, ni se pueden tampoco pronunciar sentencias justas al hilo de silogismo.

Recuérdese que ni los criterios políticos ni los preceptos jurídicos pueden ser verdaderos ni falsos. ${ }^{7} \mathrm{Ni}$ de las leyes ni de los programas políticos se puede predicar el atributo de verdad o el de falsedad. Tales preceptos y criterios son instrumentos prácticos que pueden ser enjuiciados desde los puntos de vista de otros valores, tales como: la justicia, la paz, el orden, la seguridad, la adecuación, la oportunidad, la libertad, el bienestar general, etcétera.

Tampoco puede ser verdadera ni falsa una decisión política ni una sentencia judicial.

6 Véase: Luis Recaséns Siches, Nueva filosofia de la interpretación del Derecho, México, 1956; "Unicidad en el método de interpretación del Derecho", en Estudios Jurídico. Sociales: Homenaje al Profesor Luis Legaz y Lacambra, Santiago de Compostela, 1960; "Interpretación del Derecho", en Enciclopedia Juridica Omeba, Buenos Aires, 1961; "Rivoluzione, teorica e pratica nella interpretazione del Diritto", en Rivista Internazionale de Filosofia del Diritto, 1962; "The Logic of the Reasonable as Differentiated from the Logic of the Rational in the Making and the Interpretation of the Law", en Essays of Jurispirudence in Honor of Roscoe Pound, Bobbs-Merril Co., Indianapolis-New York, 1962; "The Material Logic of the Law: A New Philosophy of Juridical Interpretation", en Archiv für Rechts- und Sozialphilosophie, 1965; Tratado general de filosofia del Derecho, $4^{\text {a }}$ ed., Editorial Porrúa, 1970; "La naturaleza del pensamiento juridico", en Revista General de Legislación y Jurisprudencia, Madrid, 1971; Experiencia juridica, naturaleza de la cosa y lógica "razonable", México, 1971.

7 Véase: Luis Recaséns Siches, Introducción al estudio del Derecho, Editorial Porrúa, México, 1970; "Filosofía de la técnica jurídica", en Diánoia, Anuario de Filosofia, México, 1969; Experiencia juridica, naturaleza de la cosa y lógica "razonable", México, 1971. 
Todo eso puede ser justo, menos justo o injusto, y puede cumplir de manera más o menos satisfactoria la inspiración de esos otros valores que he mencionado, los cuales tal vez pudiéramos englobar dentro de la denominación de prudencia.

Los programas políticos, la elaboración de las leyes y el pronunciamiento de las sentencias pueden ser enjuiciados también desde los ángulos de la posibilidad, viabilidad y de su fácil practicabilidad.

Dejemos ahora a un lado el tema de la justicia, aunque entiendo que debemos proclamar que éste es el de mayor importancia y el de más alta jerarquía. Y limitémonos a los otros valores y a las otras condiciones a que acabo de referirme, todo lo cual puede ser comprendido lato sensu bajo la denotación de prudencia.

En un primer acercamiento a este tema, yo creo que cabría describir provisionalmente la prudencia como la suma y compendio, jerárquicamente organizado, según un modo correcto, de todos los datos del problema práctico que se plantee; además, también de las respectivas significaciones de esos datos humanos; así como de todos los criterios valoradores que vengan en cuestión, primero para tratar, y luego para resolver finalmente, un problema o un conflicto de conducta humana práctica.

\section{Repulsa de la separación radical entre teoría y vida}

Por otra parte, estamos viviendo, desde hace más de medio siglo, el rechazo contra la radical separación entre la filosofía y la vida; y también contra la tajante independencia entre la teoría pura y abstracta, por un lado, y lo cotidiano habitual, por otro lado.

Fichte llevó hasta el paroxismo esta independencia cuando dijo: "filosofar es propiamente no vivir, vivir es propiamente no filosofar".

Debemos reivindicar los derechos de la vida real, del mundo del sentido común, de la existencia cotidiana, efectiva y ejecutiva, que de hecho vivimos, que viven todos, quiérase o no, incluso los filósofos y los científicos más abstractos cuando no están haciendo filosofía o ciencia.

Claro que hay verdades estrictamente filosóficas o estrictamente científicas, verdades correctas, válidas, que tenemos que aceptar, porque están justificadas desde el punto de vista filosófico o desde el científico. Pero tales verdades no anulan otro tipo de verdades pertenecientes al efectivo mundo cotidiano en que vivimos.

El profesor de la Universidad de Yale, Paul Weiss, en una conferencia pronunciada hace unos pocos años en la Universidad Nacional Autónoma de México, en apoyo de los derechos del mundo cotidiano en sentido común, relató este hecho. Una noche, en su Seminario de Filosofía, invitó a un estudiante a asomarse a la ventana para que contemplase el cielo estrellado; 
y, a continuación, le preguntó qué era lo que veía. A esta interrogación, el estudiante contestó que estaba viendo una serie de cuerpos astrales, muchos de ellos separados de la Tierra por millones de años-luz. A esta respuesta replicó el profesor Paul Weiss que eso era verdad; pero que de hecho lo que su alumno estaba viendo era el firmamento estrellado, espectáculo bello, abrumador, fuente de múltiples inspiraciones, que producía la sensación de lo ilimitado.

Una experiencia semejante fue realizada por el iusfilósofo de la Universidad de Indiana, Jerome Hall, quien una vez preguntaba a sus discipulos, enseñándoles un vaso, qué cosa era eso; y uno de ellos repuso que un conjunto de moléculas, integradas a su vez por átomos, cada uno de los cuales constituía una especie de sistema planetario ultramicroscópico. A esto replicó Jerome Hall: cierto, sin duda, pero en la realidad cotidiana esto es simplemente un vaso.

Más adelante, en este mismo estudio, mostraré cómo este tema es tratado por José Ortega y Gasset:

Ahora lo que importa es señalar que se quiere, se pide y se desarrolla hoy una filosofía no sólo de la vida, sino también para la vida, para vivir mejor, para vivir más razonablemente.

Sucede que hay dos puntos que confluyen. El punto de que la lógica pura formalista haya sido definitiva y decisivamente expulsada del campo del tratamiento de los asuntos humanos, de las decisiones en la política y en el Derecho y se preconice su sustitución por la prudencia. Y el punto de elaborar la filosofía auténtica, la cual es, primaria y sustancialmente, filosofía de la vida y filosofía para la vida.

4. ¿Por qué estudiar las aportaciones del pensamiento español al tema de la prudencia?

Pero si el asunto de la prudencia es un tema universal, ¿por qué me ocupo aquí de manera tan especial de las aportaciones españolas a esta materia?

No se trata ni remotamente de imaginar que los hispanos inventasen la prudencia, pues fantasía y no realidad sería tal suposición. Sucede, empero, que hay algunas razones que aconsejan prestar atención a lo que muchos pensadores españoles produjeron sobre este tema.

El estilo de la cultura española, y muy especialmente de la filosofía hispánica, se ha caracterizado por el desarrollo de algunas de las notas que son peculiares de la prudencia, al menos con matices muy caracteristicos.

Esto se hace patente en virtud de un fincar el pensamiento sobre la realidad práctica, así como también en virtud de una conservación de lo que podría llamarse la unidad del espíritu. Frente a la parcelación y disgregación 
de las varias disciplinas científicas, un gran número de pensadores hispanos se ha esforzado por mantener la unidad armónica del espíritu.

Además, la cultura española ha solido evitar la separación tajante entre teoría y práctica, entre pensamiento y vida; y ha aunado el uno con la otra, animado por un propósito de síntesis.

Asimismo la cultura española ha mostrado un amor delicuescente a las cosas concretas, y también una capacidad de intuición de lo singular.

A este propósito puede ser oportuno recordar que un gran número de aportaciones españolas a la filosofía se ha producido en la forma del ensayo. Del ensayo, que estriba en extraer el sentido de un tema singular y que, en torno de éste, consiste en hilar a nivel de profundidad, descubrimientos de mayor alcance.

Recuérdese además que la mayor parte de los ensayos escritos por los hispánicos, de allende y de aquende el Atlántico, entremezclan consideraciones filosóficas, históricas, políticas, sociológicas y de otros jaeces.

Muchas obras de pensamiento hispano se caracterizan también por la búsqueda de un equilibrio, del equilibrio entre los ideales y las exigencias cotidianas de la realidad de cada momento y de cada lugar. En suma, hallamos una especie de alianza entre Don Quijote y Sancho.

Claro está que todo eso no es exclusivamente español, pero sí es característicamente hispano con especiales matices propios.

Otro punto que deseo destacar es el hecho de que hay muchas contribuciones hispánicas al estudio sobre las varias dimensiones que integran la prudencia. Así como hay también grandes aportaciones a la observación del papel que la prudencia desempeña en la vida humana.

Con acierto se ha hablado del practicismo de la filosofía española, entendiéndolo en la acepción de que el buen sentido hispánico mantiene varios puntos fundamentales, entre ellos, los siguientes: 1) Todo pensamiento tiene consecuencias en el orden de la acción; y toda acción produce efectos sobre pensamientos. 2) La filosofía hispánica comprende no sólo la pura actividad teorética, sino también una serie de manifestaciones del espíritu, que cubre una amplia gama. Tiene una capacidad de síntesis, de combinación, de entretejido de valoraciones.

Prudencia es una manera de operar de la mente, cuando se emprende el cometido de afrontar problemas prácticos, de conducta humana, principalmente asuntos concernientes a las relaciones y estructuras sociales, en el mundo de los nexos familiares, en el de las funciones políticas, en el de las faenas jurídicas y en el de las tareas económicas. Y de esa actitud ante tales problemas, en el enfoque de los mismos, en términos prudentes, hallamos copiosísimos ejemplos en un sinnúmero de seres humanos, cuando éstos no se dejan obnubilar por prejuicios o por posturas antinaturales. Tal don de ponderado tratamiento de los asuntos humanos claro que no es exclusivo 
de ninguna estirpe. Pero también es cierto que en la historia hay notablemente dos linajes que han mostrado una mayor dosis de capacidad para la prudencia: los anglosajones y los hispánicos. Aunque desde luego tal común característica, en cada una de esas dos familias de pueblos, presente matices respectivamente peculiares.

Nótese que en español el número de palabras para connotar la prudencia es mayor que en alemán, que en francés, que en inglés, y que en italiano. He aquí algunos ejemplos: sensatez, cordura, discreción, circunspección, caletre, tino, solución de pro, juicio de buen varón, ingenio, ponderación, templanza, sesudez, providencia, juiciosidad, moderación, sindéresis, mesura, discernimiento, sagacidad, cautela, precaución; y, en catalán, seny.

\section{Algunas figuras y directrices ilustres de los siglos Xvı y XvII}

Luis Vives (1492-1540), considerado como la figura más destacada del Renacimiento en España, y comparado desde ciertos puntos de vista con Erasmo, elaboró una doctrina sobre el logos de la probabilidad; y estableció una diferenciación entre la razón especulativa, cuyo fin es la verdad, y la razón práctica, cuyo fin es el bien. Y además insistió mucho en los fueros de la razón práctica. Vives sacó la retórica del campo empirista y la insertó dentro de la auténtica filosofía. Sobre este tema, elaboró muy agudas consideraciones acerca de las verosimilitudes y de las conjeturas suficientemente fundadas; es decir, de aquellos razonamientos que, sin aspirar a la evidencia, se contentan con ser más verosímiles que los argumentos contrarios. De Vives hay que recordar también su teoría del juicio natural y espontáneo, basado en el testimonio inmediato de la conciencia, esto es, en una especial intuición. 8

Francisco Sánchez de las Brozas, conocido como El Brocense, en su obra Organum Dialecticum et Rhetoricum (1579) trató el tema de la retórica, del diálogo y de la deliberación como materia estrictamente filosófica; y dedicó especial atención al análisis del inventar, del disponer, del legislar y del juzgar. Expone que la razón comprende dos funciones: la de inventar o hallar, y la de disponer o juzgar en problemas prácticos. Además, desenvolvió una ruda crítica sobre muchas de las dimensiones de la silogística. El Brocense sacó la retórica de los términos del empirismo y la incluyó dentro de la genuina filosofía, ofreciendo una doctrina sobre el buen juicio o la correcta decisión.

Sebastián Fox Morcillo, en sus obras In Topica Ciceronis (1550), Compendium Ethices (1554), ofreció una ejemplar armonía para la concordia

8 Luis Vives, Introductio ad sapientiam: De Concordia et Discordia in Humano Genere: de Argumentatione: De Disputatione. Véase: Marcelino Menéndez Pelayo, La filosofia española, selección e introducción de Constantino Láscaris Comneno, Edit. Rialp, Madrid, 1964, pp. 164-174. 
entre los hechos y las ideas, ${ }^{9}$ sin perjuicio ni violentación algunos de los primeros.

Aunque dispersas en la variada multitud de sus obras, son notables las aportaciones al tema de la prudencia por Francisco de Quevedo $\left({ }^{8} 5^{80-1645}\right){ }^{10}$

Hay que mencionar también las contribuciones a este tema por Diego de Saavedra Fajardo $\left(1_{5} 4^{-1648)}\right.$, sobre todo en su obra Empresas politicas o Idea de un Principe politico cristiano representada en cien empresas, en la que abundan certeras directrices sobre el enjuiciamiento prudente de los temas legislativos y del arte de gobernar. ${ }^{11}$

Particular atención merece la teología moral casuística de los jesuitas de los siglos xvi y xvir. Recuérdese que, excepto dos, todos los casuistas atacados por Pascal eran españoles. Y a este respecto oportuno es recordar la reivindicación que de la casuística ética llevó a cabo el iusfilósofo alemán Joseph Kohler, ${ }^{12}$ así como otros movimientos ulteriores de reactualización y revaloración de esa casuística en nuestros días.

Miguel de Molinos en su Guia espiritual (1675) insiste en que un buen consejero es más conveniente que muchos libros de Ética; pues los libros hacen más daño que provecho, porque están llenos de conocimientos racionales. Por el contrario, un buen consejero procede de manera sabia y prudente, aprovechando las enseñanzas de la experiencia y atendiendo a las circunstancias reales de cada caso.

El anticipador español del criticismo, Francisco Sánchez, considerado desde algún punto de vista en cierta manera como un precursor de Descartes, aunque con tendencia hacia el escepticismo, en su obra De multum nobili et prima, universali scientia quod nihil scitur $\left(15^{81}\right),{ }^{13}$ arremete contra las vaciedades de la silogística aristotélica y escolástica. Entre otras cosas, dice lo siguiente: "¿Y cómo hemos de creer que la demostración pueda fundarse en el silogismo? Me dirás, ¡oh, escolástico!, que soy blasfemo y que merezco ser apedreado. Tú sí te mereces palos por dejarte engañar con tales trampantojos" de los silogismos.

Especial atención merecen las filigranas que sobre la prudencia escribió Baltasar Gracián (1601-1658), moralista crítico que quiere comprender y reformar al hombre, en sus obras: El discreto, El criticón y Arte de ingenio.

9 Véase: Menéndez Pelayo, op. cit., en la nota 8. Además, también la obra de Fox Morcillo, De Usu et Excercitatione Dialecticae.

10 Véase principalmente la obra: Politica de Dios y gobierno de Cristo, 1626.

11 Véase: Menéndez Pelayo, op. cit.

12 Joseph Kohler, "Die spanische Naturrechtslehrer des 16. und 17. Jahrhunderts", en Archiv für Rechts. und Wirtschafsphilosophie. Tomo X, 1917.

13 Traducida al castellano, Que Nada se Sabe, Editorial Renacimiento, Madrid; sobre Francisco Sánchez, véase: Ludwig Gerkrarth, Franz Sánchez, Ein Beitrag zur Geschichte der philosophischen Bewegungen, 1860; Cesare Giabretano, Il Pensiero de Francisco Sanchez, 19o3; E. Senchet, Essai sur la Méthode de Francisco Sánchez, professeur de Philosophie et de Medicine a l'Université de Toulouse, 1904; Joao Cruz Costa, Ensaio sobre a Vida e a Obra do Filosofo Francisco Sánchez, 1942. 
Gracián define, o mejor dicho describe, lo que él llama espíritu juicioso o discreto, lo cual podemos interpretar como prudente, en estos términos: el que todo lo descubre, nota, advierte, alcanza y comprende; el que da valor a cada cosa, califica los objetos y gradúa los sujetos; ni lo admira todo, ni lo desprecia todo, sino que lo que hace es dar a cada cosa la estimación que a ésta corresponde. Distingue entre realidades y apariencias. La prudencia es como un zahorí del entendimiento, que mira por dentro las cosas, sin pararse en la vulgar superficie de éstas. Y todavía añade: el prudente da su categoría a cada uno; da a cada dicho la estimación que merece; da a cada hecho el aprecio que le es propio; y descubre lo que haya de correcto en cada argumento prudente; y muestra exquisito reparo, profunda observación y sutil advertencia, esto es, capacidad de notar, de ponderar. Esta discreción no es tanto especulativa sino más bien muy práctica, pues descubre las razones para la distribución. Pesa los respectivos méritos de cada uno de los argumentos y elige con arte. Posee una gran comprensión de los objetos y más todavía de los sujetos. Resuelve con extremada sindéresis, decreta con plausible elección. Es detenido y minucioso, pues del mucho advertir nace el reparar. Además, descubre todos los inconvenientes que determinada decisión pueda acarrear, y suministra para esto todos los medios oportunos encaminados a prevenir tales perjuicios. La prudencia puede llamarse también entereza. Es corona de la discreción; es el saber filosofar, sacando de todo, como solícita abeja, o la miel del provecho o la cera para la luz del desengaño.

\section{Siglos xuiii y xix}

Fray Benito Jerónimo Feijóo (1676-1764) en su Teatro critico universal ... sobre todo género de materias para desengaño de errores comunes o Cartas eruditas, en una postura antiescolástica, mostró una tendencia al experimentalismo, pues enamorábale el gran magisterio de la experiencia, no sólo de la experiencia científica, sino también de la experiencia vital o práctica. Su obra fue traducida al inglés y al italiano.

Esteban de Arteaga (1747-1799), en su obra Indagaciones, subrayó en materia de la acción práctica, una especie de empirismo psicológico, que se centra en el estudio de los efectos y hace a un lado premisas antecedentes y causas, lo cual lo convierte en cierta manera en una especie de modesto predecesor de la filosofía de John Dewey; en tanto que le interesa más el contraste de los resultados que las consecuencias formalistas de los principios.

Parece oportuno traer al recuerdo la figura de Jaime Balmes (1810-1848), aquel filósofo católico decididamente antiescolástico, que tan certeras y sarcásticas críticas escribió sobre la esterilidad de los silogismos. Aunque Balmes no construyó propiamente una doctrina del logos de lo humano, sucede 
que, de hecho, la desplegó prolijamente en múltiples derivaciones de esa lógica razonable, en su obra que lleva por título El criterio. Allí mostró su desdén contra la silogística, pues el silogismo nunca es el meollo de conocimiento justificado sino que es tan sólo un expediente auxiliar. En ese mismo libro hizo aportaciones a los siguientes temas, relacionados con la prudencia: la imposibilidad de ciertas conductas; las reglas para la apreciación de las pretendidas pruebas de hechos humanos; el método para la crítica del testimonio; la importancia de la intuición práctica; el valor del tino y de la sensatez; el justificado papel del pensamiento emocional en materia práctica; el problema de la elección de los fines y de la búsqueda de los medios con buen sentido. En realidad, desarrolló una especie de lógica práctica, así como una guía para el enjuiciamiento ético. Cabe calificar esa obra como una especie de guía de prudencia, sensatez y cordura.

$\therefore$ Juan Donoso Cortés (1809-1853), aunque desventuradamente en la segunda etapa de su pensamiento estuvo decisivamente influido por la escuela francesa de la Restauración, aportó al tema de la prudencia una justificada crítica contra el doctrinarismo en materia política, como algo que es estéril e impotente y que suele conducir a grandes catástrofes. ${ }^{14}$

El filósofo catalán Francisco Xavier Llorens y Barba (1820-1872), quien españolizó la escuela escocesa del sentido común, sacó la retórica del marco de un simple empirismo y logró incluirla dentro de una auténtica y rigorosa filosofía. ${ }^{15}$

\section{Contribución de Leopoldo Eulogio Palacios}

En nuestros días, Leopoldo Eulogio. Pálacios ha escrito sobre la prudencia un muy valioso estudio, lleno de aciertos y preñado de estímulos, sobre todo por lo que atañe a los campos de la política y del Derecho. ${ }^{\mathbf{1 6}}$

La prudencia es, en la política y en el Derecho, la conciliación entre el doctrinarismo y el oportunismo.

El doctrinarismo se funda en el reconocimiento de unos principios que se supone son intrínsecamente válidos, necesarios, universales y perennes.

Es cierto que hay criterios éticos con necesaria validez. En efecto, podemos referirnos a pautas ideales que en moral poseen esencialmente inherente validez.

Pero el doctrinarismo puro exacerbado es ciego para las exigencias de lo concreto, para las demandas de lo singular, de lo individual y es ciego también para las mutaciones históricas y para los fenómenos del cambio social.

14 Las obras principales de Juan Donoso Cortés son, de su primera época: Lecciones de Derecho politico, profesadas en el Ateneo de Madrid; y, de su segunda época: Ensayo sobre el catolicismo, el liberalismo y el socialismo, 1851.

15 Francisco Javier Llorens y Barba, Lecciones de filosofia, 1864-65.

16 Eulogio Palacios, La prudencia politica, $3^{\text {a }}$ ed., Edit. Rialp, Madrid, 1967. 
Por otra parte, en sí, el oportunismo no es esencialmente malo. Puede ser muy bueno. Practica el condicionamiento de las decisiones a las circunstancias de lugar y de tiempo. Pero si se ejerce el oportunismo sin limitaciones, nos lleva arrastrados a la deriva sin norte y sin brújula.

La prudencia recoge de esas dos posturas extremosas - del doctrinarismo y del oportunismo-, todo cuanto cada una de ambas encierra de positivo y ventajoso; y anula mediante una síntesis unitaria superior, todo cuanto las dos entrañan de perjudicial y de negativo.

La prudencia atiende a las circunstancias de la vida humana y de sus situaciones; pero no es una pasional y arbitraria veleta, que se mude a todos los vientos sin estabilidad ni firmeza.

Palacios forja el término prudencialismo para designar "una razón que no vaya exclusivamente a los principios inmutables y eternos, y que atienda también a lo temporal y contingente...; es una cualidad de la razón práctica, que guía nuestro vivir, entendiéndolo en su concreción máxima, y revestido de todas sus circunstancias".

\section{Las contribuciones de Miguel de Unamuno y de José Ortega y Gasset}

Donde encontramos un avance a grandes zancadas en este tema de la prudencia es en Unamuno y en Ortega y Gasset.

En ambos, se trata de la versión de la prudencia en términos de la razón vital. Este avance, sobre todo en el que se produjo por obra de Ortega y Gasset, significa el ingreso de la prudencia en la filosofía rigorosa por la puerta grande, mejor dicho, por la puerta central de ella, hasta convertirse en un nervio mismo de la metafísica.

Con Ortega, la prudencia se convierte en una parte medular en el meollo de una auténtica filosofía; se torna, en tanto que razón vital e histórica, la columna vertebral de una nueva metafísica. Porque esa nueva metafísica de Ortega y Gasset es precisamente filosofía de la vida humana. Y no es sólo eso, sino que, además, es filosofía para la humana existencia.

La contribución de Unamuno consistió en una embestida audaz, feroz, aunque plenamente justificada, contra la lógica pura; $\mathrm{y}$, además, se constituyó en una especie de Leitmotiv de toda su obra.

Veamos este párrafo asestado por Unamuno contra el abuso de la razón de tipo matemático llevada a campos que son ajenos a ésta: lo español genuino, como modo original de vivir, es "hacer que nuestra verdad del corazón alumbre las mentes contra todas las tinieblas de la lógica y del raciocinio".17 ¡Nada menos que esto! En fin de cuentas, se trata del desahucio de la razón pura por la razón prudencial. Y no es una paradoja unamunesca. No es una pueblos.

17 Miguel de Unamuno, El sentimiento trágico de la vida en los hombres y en los 
paradoja ni tampoco una boutade del gran don Miguel, a las que el Rector de la Universidad de Salamanca era tan aficionado. Se trata de una convicción que impregna toda la obra de Unamuno; y que él justifica sobradamente en su producción, que bien pudiera llamarse de antropología filosófica. Su antropología filosófica y sus comentarios políticos operan siempre con el hombre de carne y hueso, con el individuo auténtico, siempre singular $\mathrm{y}$ único.

Pasemos ahora al pensamiento de José Ortega y Gasset. ${ }^{18}$ En Ortega y Gasset encontramos cuatro puntos cimentadores de toda su reflexión filosófica:

Primero: el descubrimiento de que el hombre hace filosofía y hace ciencia por virtud de que ha menester de ambas, porque las necesita para sostenerse en el mundo, para sobrevivir en éste.

Segundo: con la ciencia y la filosofía el hombre intenta averiguar qué son auténticamente, en verdad, las cosas. Pero eso lo hace para dominar las cosas, para producirlas cuando no las tiene a su vera y las necesita. En fin de cuentas, ciencia y filosofía son técnicas para la vida.

Tercero: el mundo o trasmundo espectral de la ciencia y de la filosofia no suprimen, no anulan el mundo del sentido común, que es el que efectivamente seguimos viviendo de hecho y en una forma ejecutiva, y a cuyas condiciones estamos sujetos, querámoslo o no, y al que tenemos que atenernos.

Cuarto: exploró la razón vital y la razón histórica que habian sido abocetadas por Dilthey.

Veamos con mayor detalle estos cuatro puntos.

Las cosas están ahí en mi vida. Antes de que yo piense sobre ellas no manifiestan su ser. Esta luz me alumbra, pero no tengo su ser. Cuando se apaga, se convierte en problema, porque la necesito y entonces no la tengo. El suelo me sostiene. Pero súbitamente tiembla. Entonces me hago cuestión del suelo; éste se convierte en problema.

El pensamiento comienza a funcionar, pues, disparado por la urgencia vital, pre-intelectual. Si el mundo en torno respondiese a todas mis necesidades o menesteres, yo no me habría hecho cuestión de nada en ese mundo; no se me habría ocurrido pensar sobre nada; y ni siquiera tendría la idea de necesitar, de haber menester del pensamiento.

Pensar y hablar es manifestar, declarar o aclarar, descubrir lo oculto.

El ser de las cosas, pues, resulta que, por de pronto, consiste en una necesidad del hombre.

Lo que primariamente es cuestión para nosotros es nuestro hacer, nuestra

18 José Ortega y Gasset, Obras Completas, 6 volúmenes, Revista de Occidente, Madrid, 1946 y 1947; y las antes inéditas, publicadas póstumamente: ¿Qué es filosofia?, Revista de Occidente, 1958; Apuntes sobre el pensamiento, Colección El Arquero, Madrid, $2^{\mathrm{a}}$ ed., 1966; Origen y epilogo de la filosofia, El Arquero, $2^{\natural}$ ed., Madrid, $19^{6} 7$; y Unas lecciones de metafisica, $2^{\mathfrak{a}}$ ed., Alianza Editorial, Madrid, 1968, principalmente esta última obra. 
acción. Hay, por lo tanto, una primacía de la práctica $y$, por ende, de la prudencia.

Busco y construyo la verdad sobre la luz, sobre la tierra que me sostiene, para controlarlas.

Todo pensamiento, incluso el pretensamente más puro y contemplativo es un caso particular de la actividad técnica del hombre.

El hombre es Homo sapiens, porque es Homo faber, y no a la inversa, como erróneamente suele decirse.

No se puede hacer con la madera del árbol ni el más sencillo taburete, si antes no se ha hecho un mínimum de teoría sobre la madera.

Estar en el mundo con las cosas, empleando estas palabras como concepto expresivo de la realidad primaria que es nuestra vida, significa simplemente "habérnosilas con" esto o lo otro; usar de esto; manejar aquello; servirse de algo.

Ortega, con precedencia a otros filósofos del siglo $\mathrm{xx}$, hizo la diferencia entre el mundo de los objetos cotidianos en que nos movemos, esta mesa, esta sala, el sillón, las lámparas, por una parte; y, por otra parte, los objetos científicos, por ejemplo: esta mesa es un conjunto de cargas eléctricas moviéndose a gran velocidad, pero su volumen en total no alcanza ni siquiera una millonésima parte del volumen de la mesa, tenuemente disgregada en una región casi toda vacía. Ésta es la verdad teorética; pero no es la verdad práctica. La física moderna jamás logrará exorcizar la primera mesa en la cual apoyo el papel sobre el que estoy escribiendo y mis brazos.

Los objetos, las cosas de la vida cotidiana son o facilidades o dificultades de mi existencia: me sirven o me desirven, me favorecen o me perturban.

En alguna medida cabe decir que depende lo que la circunstancia sea de quién sea yo.

Esto transfiere a mi el problema del ser de las cosas. Este ser de las cosas depende de lo que sea yo y de lo que yo necesite o tenga que hacer. Una vez más, nos encontramos con el primado de la práctica sobre la teoría. En fin de cuentas afrontamos siempre el problema de lo posible y lo imposible en nuestra vida. La vida es siempre tener que hacer algo en vista de las circunstancias en que estamos; tener que ocuparse con algo.

Tengo que habérmelas con el "ahi", con el "ahora" y conmigo mismo y con mis prójimos.

Aquí destacadamente vuelve a aparecer el tema de la prudencia en cuanto a lo que debo de hacer respecto de mis prójimos. Se trata del problema de la orientación de mí mismo frente a mis prójimos. Se trata de saber qué debo de hacer en mis relaciones con ellos, especialmente en las situaciones conflictivas.

Aquí la idea de la prudencia asoma el morro encapsulada bajo la palabra "saber". Saber a qué atenerse con respecto a algo; con respecto a 
una situación; y precisamente aquí y ahora; saber lo que hay que hacer con todo eso y en vista de todo eso.

Ortega llega a un radicalismo de la prudencia y simultáneamente a una depreciación del raciocinio puro de tipo matemático - fuera del campo de la matemática donde es legítimo- y al desenvolvimiento de la razón vital. Pero llega todavía más lejos. Dice con detonante valentía: "el ingreso ejemplar en la inmensa extravagancia de esa filosofía que nos ofrece Parménides, el loco de la Razón, quien, con un radicalismo nunca emparejado con otro, nos proporciona la impresión vivaz de la inmensa insensatez que es la lógica pura".

La prudencia, en gran parte, aparece en la obra orteguiana bajo la versión de la razón vital y de la razón histórica.

Hasta ahora, por lo general, se había considerado que la historia era lo contrario de la razón; y que la vida era lo diverso de la teoría. En Grecia, los términos razón e historia eran contrapuestos. Y es que hasta ahora, en efecto, apenas se ha ocupado nadie de buscar en la historia su sustancia racional. El que más, ha querido llevar a ella una razón forastera, como Hegel, que inyecta en la historia el formalismo de su lógica, o Buckle, la razón fisiológica y física. El propósito de Ortega y Gasset es estrictamente inverso. Se trata de encontrar en la vida humana misma y en la historia misma su original y autóctona razón. No una razón extravital ni extrahistórica, que parezca cumplirse en la existencia humana y en la historia, sino literalmente, lo que al hombre le ha pasado, constituyendo la sustantiva razón, la revelación y la realidad, trascendentes a las teorías del hombre, y que son este mismo hombre por debajo de sus teorías.

La razón vital e histórica es, pues, ratio, logos, rigoroso concepto. $\mathrm{Al}$ oponerla a la razón físico-matemática no se trata de conceder permisos de irracionalismo. Al contrario, la razón histórica es todavía más racional que la física, más rigorosa, más exigente que ésta. La física renuncia a entender aquello de lo que ella habla. La razón vital y la razón histórica, en cambio, no aceptan nada como mero hecho, sino que fluidifican todo hecho en el fieri de que proviene: de cómo se hace el hecho. No cree aclarar los fenómenos humanos reduciéndolos a un repertorio de instintos y "facultades" -que serian, en efecto, hechos brutos, como el choque y la atracción en física-, sino que muestra lo que el hombre hace con esos instintos y facultades; inclusive nos declara cómo han venido a ser esos "hechos" - los instintos y las facultades-, que no son, claro está, más que ideas -interpretacionesque el hombre ha fabricado en una cierta coyuntura de su vivir.

Nos encontramos con esa razón vital e histórica, que es tan distinta de la venerable razón pura. Y aquella, sin embargo, es todo lo contrario de vaguedades, metáforas, utopías y misticismos. La razón vital es una razón mucho más razonable que los silogismos de Aristóteles. 
El hombre no sólo va viviendo su vivir, sino que, conforme lo va hacien. do, se va formando en él una idea o conocimiento de lo que es la vida. Es a eso a lo que Ortega llama experiencia de la vida.

Esta experiencia es un saber que no queda como el saber científico, más o menos fuera de la vida de quien lo posee, sino que la experiencia de la vida forma parte integrante de la vida misma.

Si hay media docena de altísimos asuntos, uno de ellos es sin duda la experiencia de la vida, que brota en la raiz misma de la humana existencia.

Las cosas que nos pasan van dejando en nosotros, por sí mismas, un precipitado que cristaliza en algo así como reglas, como recetas, regularidades, las cuales, a su vez, articuladas unas en otras van dibujando el perfíl de lo que es la vida.

Glosando yo por mi cuenta estos pensamientos orteguianos diría que los temas de la prudencia pertenecen no al mundo de las naturalidades como los triángulos, la casa, la encina y el canguro. Pertenecen a lo humano; y puesto que pertenecen a lo humano, tienen estructura histórica; lo que hace que la humana existencia sea histórica, la cual lo es por necesidad.

El triángulo equilátero en que pensaba Arquímedes hace 23 siglos en Siracusa, es el mismo que hoy piensa un muchacho de nuestra ciudad al que su maestro le está enseñando geometría.

En física nos encontramos con leyes de causalidad inexorables. En cambio, los objetos humanos son históricos. Por de pronto, hay que narrarlos. "La narración es una forma de la razón en el sentido más superlativo de este nombre - una forma de la razón al lado y frente a la razón física, frente a la razón matemática, y frente a la razón lógica racional.

"La razón histórica, que no consiste en inducir ni en deducir, sino lisamente en narrar, es la única capaz de entender las realidades humanas, porque la contextura de éstas consiste en ser históricas, es historicidad."

De lo dicho se desprende que toda realidad humana, por su historicidad, consiste en venir de algo pasado y en ir hacia algo futuro. Por lo tanto, es una realidad sustantivamente móvil.

El hombre para vivir tiene que ir eligiendo entre las posibilidades que le ofrece su circunstancia. Para decidirse, el hombre necesita tener motivos; y esos motivos son los que solemos llamar razones, argumentos. En la actualidad Perelman, el filósofo belga, define la prudencia como el arte de la argumentación.

Además es patente que Ortega y Gasset no sólo distingue lo teorético de lo práctico, sino que en alguna medida da la primacía a la praxis. "La metafísica o la geometría están ahí, porque unos hombres las crearon merced a un rudo esfuerzo; y si emplearon este esfuerzo fue porque necesitaban aquellas disciplinas, porque las habian menester, porque no podían prescindir de ellas. Eso que buscaron y encontraron se adecuaba a la necesidad que 
sentían, a una necesidad previamente sentida." Una serie de ideas, aunque las entendamos, carecen de sentido si es que no las estamos necesitando.

El sentido de la filosofía es incitarnos a tener cuidado de nuestra vida, a acuitarncs sobre ella, y a lograr caminos de prudencia.

LuIs RECASÉNS SICHES

Instituto de Investigaciones Filosóficas

Universidad Nacional Autónoma de México 